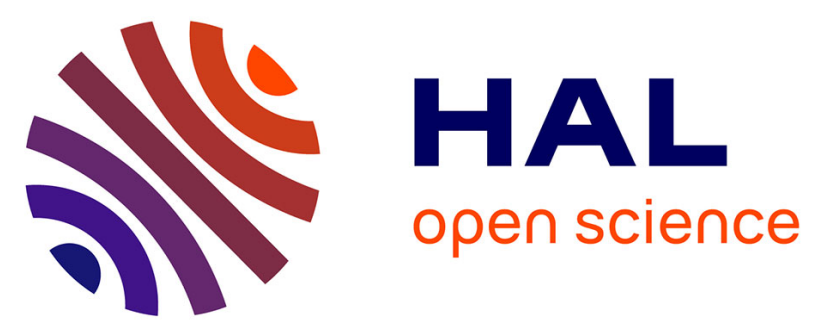

\title{
Thermal modelization and experiments on the current of superconducting microbridges dependence to light in the 10-90K range
}

Eric Mossang, Pierre Langlois, Christophe Dolabdjian, Didier Robbes, Daniel Bloyet, J. Hamet, Olivier Thomas

\section{To cite this version:}

Eric Mossang, Pierre Langlois, Christophe Dolabdjian, Didier Robbes, Daniel Bloyet, et al.. Thermal modelization and experiments on the current of superconducting microbridges dependence to light in the 10-90K range. Physica B: Condensed Matter, 1994, 194-196, pp.2125-2126. hal-00720436

\section{HAL Id: hal-00720436 https://hal.science/hal-00720436}

Submitted on 24 Jul 2012

HAL is a multi-disciplinary open access archive for the deposit and dissemination of scientific research documents, whether they are published or not. The documents may come from teaching and research institutions in France or abroad, or from public or private research centers.
L'archive ouverte pluridisciplinaire HAL, est destinée au dépôt et à la diffusion de documents scientifiques de niveau recherche, publiés ou non, émanant des établissements d'enseignement et de recherche français ou étrangers, des laboratoires publics ou privés. 
Thermal modelization and experiments on the current of superconducting microbridges dependence to light in the $10-90 \mathrm{~K}$ range

Pierre Y. Langlois ${ }^{a}$, Christophe P. Dolabdjian ${ }^{a}$, Didier P. Robbes ${ }^{a}$, Daniel Bloyet ${ }^{a}$, Jean F. Hamet ${ }^{b}$, Eric Mossang ${ }^{\mathrm{c}}$ and Olivier Thomas ${ }^{\mathrm{c}}$.

a : Electronic and Instrumentation Laboratory, ISMRA, Bd Mal Juin - F 14050 CAEN cedex, FRANCE

b : Crismat Laboratory, ISMRA, Bd Mal Juin - F 14050 CAEN cedex, FRANCE

c : LMGP - ENSPG, URA CNRS - 1109 - BP 46 - F 38042 St MARTIN d'HERES, FRANCE

We have previously reported (Applied Superconductivity Conference 1992) that the critical current $I_{c}$ dependence versus optical power $P$ in the $\mathrm{mW}$ range at $780 \mathrm{~nm}$, with $P$ focused on microbridges of YBCO thin films, could be calculated using simple calculations on heat production in the superconducting film and heat conduction to the substrate. The model was valid only on a limited range of temperature $T$ where the thermal boundary resistance $R_{b d}$ lying at the film-substrate interface could be taken as a constant $R_{o}=10^{-3} \mathrm{Kcm}^{2} / \mathrm{W}$. We present a full model obtained by integration of the coupled Fourier equations giving the temperature dependence in the superconducting anisotropic YBCO film and in its substrate. We show that the thermal boundary resistance modelized as $R_{b d}(T)=$ $B / T^{3}+R_{0}$, with $B / T^{3}$ given by the acoustic mismath model, is still limiting the heat transfer from the film to the substrate at least down to $10 \mathrm{~K}$. As a consequence, a simple model that only uses $R_{b d}(T)$ and $\mathrm{dI}_{c} / d T$ is derived which allows realistic evaluations of the current sensitivity $S_{I}(P, T)$ to the applied power $P$ over the $10-90 \mathrm{~K}$ temperature range Calculated $S_{\mathrm{I}}(\mathrm{P}, \mathrm{T})$ which lies in the $0.1-1 \mathrm{~A} / \mathrm{W}$ range agrees well with those measured on $\mathrm{YBCO} / \mathrm{MgO}$ or $\mathrm{YBCO} / \mathrm{SrTiO}_{3}$ devices.

\section{1.- INTRODUCTION}

As shown in [1], the full interpretation of light interaction with high $\mathrm{T}_{\mathrm{c}}$ superconducting thin films is still an open problem. These authors have identified the important thermal process that occurs at the film substrate interface and which leads to thermal energy transport across the boundary in nanoseconds. This work [1] was very useful to enforce the hypothesis of the bolometric response on this time scale at the transition temperature $T_{C}$ of the film, namely : $\mathrm{YBa}_{2} \mathrm{Cu}_{3} \mathrm{O}_{7}$. The search of non bolometric components of the response below $T_{C}$ can then be done via the current voltage (I-V) characteristic of microbridges and their sensitivities to light focused upon them. Again the bolometric component has to be removed and in [2] we suggested the use of the critical current $\left(I_{C}\right)$ versus temperature $(\mathrm{T})$ dependence as the thermometer needed to evaluate the temperature rise of the device exposed to light. The model valid down to $60 \mathrm{~K}$, shows no evidence of non bolometric response. We now present the results of a more detailed study, valid down to $10 \mathrm{~K}$, which lead to correct estimations of bolometric effects on critical current of superconducting mictrobridges.

\section{2- EXPERIMENTS}

We have tested thin films of $\mathrm{YBa}_{2} \mathrm{Cu}_{3} \mathrm{O}_{7}$. deposited by laser ablation on (100) $\mathrm{Mg0}$ with thickness of $200 \mathrm{~nm}$ and a high quality $\mathrm{YBa}_{2} \mathrm{Cu}_{3} \mathrm{O}_{7}$. epitaxial layer synthesized by MOCVD [3]. The crystallographic orientation of the latter has been checked by x-ray diffraction. A $\theta / 2 \theta$ scan shows a strong $\mathrm{c}$-axis orientation as evidenced by the absence of any other diffraction lines apart from the 001 one. Pole figures recorded on samples grown in similar conditions show a very good in-plane orientation. The film thickness was $40 \mathrm{~nm}$.

The experimental arrangement was described elsewhere [2]; briefly the thin films were patterned in microbridges or meanders a few $\mu \mathrm{m}$ in width using standard photolithographic technics. The samples were placed on a cold finger in a window cryostat. The light source is a laser diode at $790 \mathrm{~nm}$ with a very low astigmatism. It is focused on microbridges ( $11 \mu \mathrm{m}$ FWHM). Positioning of the spot is done using a CCD camera mounted on binocular lenses. The laser diode can be small signal modulated at frequencies up to $200 \mathrm{MHz}$. 
Typical results of measurements are reported in the figure. They give critical current densities and current sensitivities $S_{I}$ as a function of temperature. $S_{I}$ is the variation in critical current $I_{C}$ when an optical power $P$ is applied, and $S_{I}$ is recorded using a low noise voltage regulation. Results are compared to those of the model and discussed in the conclusion.

\section{3-MODEL AND DISCUSSION}

The Fourier equations governing the heat conduction in the system vacuum - YBCO substrate was written as done in [4] but extended to the three dimensional case, using a cylindrical coordinate system centered on the incident spot light (normal incidence). To integrate the system [5], we assume the thermal emission at the film surface as well as the heat flux entering the back of the film are neglectable. The substrate is considered as a semi infinite medium, and the dominant heat production is $1 / 2 \sigma_{1}|\mathrm{E}|^{2}$ where $\sigma_{1}$ is the real part of the conductivity at optical frequencies [6] and $E$ is the electric field amplitude in YBCO (refractive index needed for calculation may be found in [4] [6]). Finally, to get the temperature discontinuity at the film substrate interface, we set the thermal boundary resistance $\mathrm{R}_{\mathrm{bdd}}$ to be the sum of its high temperature limit Ro $\cong 10^{-3} \mathrm{Kcm}^{2} / \mathrm{W}(1)$, and of its low temperature limit $\mathrm{B} / \mathrm{T}^{3}$ with $\mathrm{B}=17 \mathrm{~K}^{4} \mathrm{~cm}^{2} / \mathrm{W}$ from the acoustic mismatch model. Once the temperature profile is deduced from the Fourier equation and using the critical current density $\mathrm{j}_{\mathrm{c}}(\mathrm{T})$ data recorded in the dark, we calculate the local $\mathrm{j}_{\mathrm{c}}$ value under light : a sum over the microbridge leads to the modified critical current. The current sensitivity which is then deduced is reported in the lower part of the figure. The calculated points (squares) show a good agreement with the experimental ones. The numerical calculation being rather heavy and since the detailed analysis lead to the conclusion that most of the temperature drop is at the film substrate interface, we introduced as described in [ 2] a simplified way to get $S_{\mathrm{I}}$. First, the mean excess temperature $\Delta T$ of the exposed part of the film is roughly given by :

$$
\Delta T(\omega)=\eta p(\omega) R_{\mathrm{bd}}(T) /\left(1+\omega^{2} \tau^{2}\right)^{0.5}
$$

with $\eta$ absorbtion coefficient, $p(\omega)$ optical power flux at pulsation $\omega$ and $\tau$ thermal time constant. Second, $S_{I}$ is written as : $S_{I}=\Delta T(\omega) \times d_{C}(T) / d T$, which again compares favorably to experimental data.

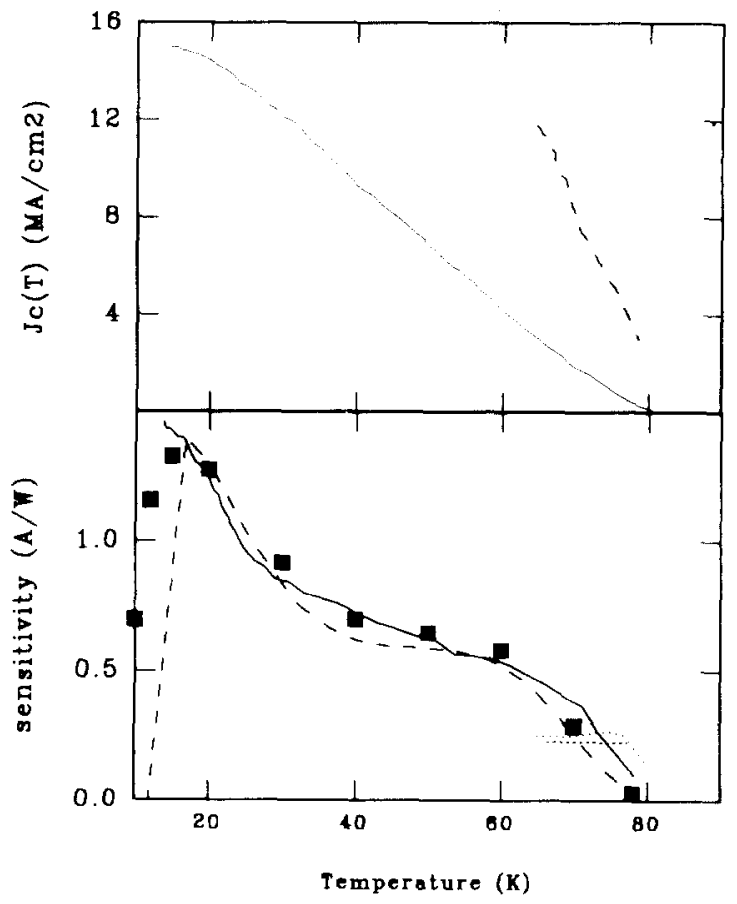

upper curves: - - $\mathrm{j}_{\mathrm{c}}(\mathrm{T})$ of a $0.1 \times 7 \times 15 \mu \mathrm{m}^{3}$ YBCO/MGO bridge (a).---- $j_{c}(\mathrm{~T})$ of a. $04 \times 25 \times 100 \mu \mathrm{m}^{3}$. YBCO/SrTiO 3 bridge (b)

lower curves :- bridge (a) response $(\eta \cong 0.5)$. .....bridge (b) response. $(\eta \cong 0.2)$ calculated response (full model) -...- calculated response (simplified calculations).

\section{REFERENCES}

[1] M.Nahum, S. Verghese, P.L. Richards and K. Char, Appl Phys. Lett. 59, n 16 (1991) 2034.

[2] D. Robbes, P. Langlois, C. Dolabdjian, D. Bloyet, J.F. Hamet and H. Murray, to appear in IEEE Trans. Appl. Supercond.3 (1993)

[3] O. Thomas, A. Pisch, E. Mossang, F. Weiss, R. Madar, J.P. Senateur, J. Less Comm. Metals $164 \& 165,444$ (1990)

[4] M.I. Flik, Cryogenics 30 (1990) 1118

[5] P. Langlois, Forthcoming Ph. D. dissertation

[6] D.E. Aspnes and M.K. Kelly, IEEE Quant El $25,11(1989) 2378$. 